\title{
A comparison of very old patients admitted to intensive care unit after acute versus elective surgery or intervention
}

\author{
Christian Jung a,*,1, Bernhard Wernly ${ }^{\mathrm{b}, 1}$, Johanna M. Muessig a , Malte Kelm ${ }^{\mathrm{a}}$, Ariane Boumendil c \\ Alessandro Morandi ${ }^{\mathrm{d}}$, Finn H. Andersen ${ }^{\mathrm{e}}$, Antonio Artigas ${ }^{\mathrm{f}, \mathrm{x}}$, Guido Bertolini ${ }^{\mathrm{g}}$, Maurizio Cecconi ${ }^{\mathrm{h}}$, \\ Steffen Christensen ${ }^{i}$, Loredana Faraldi ${ }^{j}$, Jesper Fjølner ${ }^{i}$, Michael Lichtenauer ${ }^{b}$, Raphael Romano Bruno ${ }^{a}$,
} Brian Marsh ${ }^{\mathrm{k}}$, Rui Moreno ${ }^{\mathrm{l}}$, Sandra Oeyen ${ }^{\mathrm{m}}$, Christina Agvald Öhman ${ }^{\mathrm{n}}$, Bernardo Bollen Pinto ${ }^{\mathrm{B}}$, Ivo W. Soliman ${ }^{\mathrm{p}}$, Wojciech Szczeklik ${ }^{\mathrm{q}}$, Andreas Valentin ${ }^{\mathrm{r}}$, Ximena Watson ${ }^{\mathrm{s}}$, Tilemachos Zafeiridis ${ }^{\mathrm{t}}$, Dylan W. De Lange ${ }^{\mathrm{u}}$, Bertrand Guidet ${ }^{\mathrm{v}, \mathrm{y}, \mathrm{z}}$, Hans Flaatten ${ }^{\mathrm{w}}$, on behalf of the VIP1 study group ${ }^{2}$

a Dep. of Cardiology, Pulmonology and Angiology, University Hospital, Düsseldorf, Germany

b Department of Cardiology, Paracelsus Medical University, Salzburg, Austria

c Assistance Publique-Hôpital de Paris, Hôpital Saint-Antoine, Service de Réanimation Médicale, Paris F-75012, France

d Department of Rehabilitation Hospital Ancelle di Cremona, Italy, Geriatric Research Group, Brescia, Italy

e Dep. Of Anaesthesia and Intensive Care, Ålesund Hospital, Ålesund, Norway. NTNU, Dep of Circulation and Medical Imaging, Trondheim, Norway

${ }^{\mathrm{f}}$ Department of Intensive Care Medecine, CIBER Enfermedades Respiratorias, Corporacion Sanitaria Universitaria Parc Tauli, Autonomous University of Barcelona, Sabadell, Spain

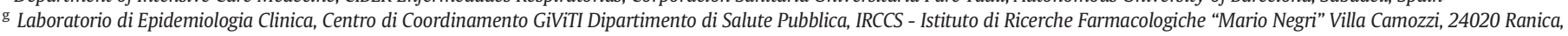
Bergamo, Italy

${ }^{\mathrm{h}}$ Department of Anaesthesia IRCCS Instituto Clínico Humanitas, Humanitas University, Milan, Italy

i Department of Anaesthesia and Intensive Care Medicine, Aarhus University Hospital, Denmark

${ }^{j}$ Grande Ospedale Metropolitano Niguarda, Milano, Italy

${ }^{\mathrm{k}}$ Mater Misericordiae University Hospital, Dublin, Ireland

${ }^{1}$ Unidade de Cuidados Intensivos Neurocríticos. Hospital de São José, Centro Hospitalar de Lisboa Central, Faculdade de Ciência Médicas de Lisboa, Nova Médical School, Lisbon, Portugal

${ }^{\mathrm{m}}$ Department of Intensive Care 1K12IC Ghent University Hospital, Ghent, Belgium

${ }^{n}$ Karolinska University Hospital, Sweden

- Geneva University Hospitals, Geneva, Switzerland

${ }^{\mathrm{P}}$ Department of Intensive Care Medicine, University Medical Center, University Utrecht, Utrecht, the Netherlands

${ }^{\mathrm{q}}$ Intensive Care and Perioperative Medicine Division, Jagiellonian University Medical College, Kraków, Poland

${ }^{\mathrm{r}}$ Kardinal Schwarzenberg Hospital, Schwarzach, Austria

s St George's University Hospital, London, UK

${ }^{\mathrm{t}}$ Intensive Care Unit General Hospital of Larissa Tsakalof Larissa, Greece

u Department of Intensive Care Medicine, University Medical Center, University Utrecht, the Netherlands

${ }^{\vee}$ Hôpitaux de Paris, Hôpital Saint-Antoine, service de réanimation médicale, Paris, F-75012, France

${ }^{w}$ Department of Clinical Medecine,University of Bergen, Department of Anaestesia and Intensive Care, Haukeland University Hospital, Bergen, Norway

x Department of Intensive Care Medecine, University Hospitals Sagrado Corazón and General de Catalunya. Quirón Salud. Barcelona-Sant Cugat, Spain

y Sorbonne Universités, UPMC Univ Paris 06, UMR_S 1136, Institut Pierre Louis d'Epidémiologie et de Santé Publique, F-75013 Paris, France

${ }^{\mathrm{z}}$ INSERM, UMR_S 1136, Institut Pierre Louis d'Epidémiologie et de Santé Publique, F-75013 Paris, France

\footnotetext{
* Corresponding author at: Division of Cardiology, Pulmonology, and Vascular Medicine, University Duesseldorf, Moorenstraße 5, 40225 Duesseldorf, Germany.

E-mail addresses: Christian.Jung@med.uni-duesseldorf.de (C. Jung), bernhard@wernly.at (B. Wernly), johanna.muessig@med.uni-duesseldorf.de (J.M. Muessig), malte.kelm@med.uni-duesseldorf.de (M. Kelm), finn.andersen@ntnu.no (F.H. Andersen), aartigas@tauli.cat (A. Artigas), guido.bertolini@marionegri.it (G. Bertolini), Maurizio.cecconi@huamitas.it (M. Cecconi), steffen.christensen@auh.rm.dk (S.Christensen), loredana.faraldi@ospedaleniguarda.it (L. Faraldi), jespfjoe@rm.dk (J. Fjølner), m.lichtenauer@salk.at (M. Lichtenauer), raphael.bruno@med.uni-duesseldorf.de (R.R. Bruno), bmarsh@mater.ie (B. Marsh), r.moreno@mail.telepac.pt (R. Moreno), Sandra.Oeyen@UGent.be (S. Oeyen), christina.agvald-ohman@sll.se (C.A. Öhman), i.w.soliman@umcutrecht.nl (I.W. Soliman),wojciech.szczeklik@uj.edu.pl (W. Szczeklik), Andreas.Valentin@ks-klinikum.at (A. Valentin), ugm2xw@doctors.org.uk (X.Watson), d.w.delange@umcutrecht.nl (D.W. De Lange), bertrand.guidet@aphp.fr (B. Guidet), hans.flaatten@uib.no (H. Flaatten).

1 These authors share equally contributing first authorship.

${ }^{2}$ VIP1 study group
} 


\section{A R T I C L E I N F O}

\section{Keywords:}

Critically ill

Frailty

Elective

Outcome

Older

Old

\section{A B S T R A C T}

Background: We aimed to evaluate differences in outcome between patients admitted to intensive care unit (ICU) after elective versus acute surgery in a multinational cohort of very old patients ( $\geq 80$ years; VIP). Predictors of mortality, with special emphasis on frailty, were assessed.

Methods: In total, 5063 VIPs were included in this analysis, 922 were admitted after elective surgery or intervention, 4141 acutely, with 402 after acute surgery. Differences were calculated using Mann-Whitney- $U$ test and Wilcoxon test. Univariate and multivariable logistic regression were used to assess associations with mortality. Results: Compared patients admitted after acute surgery, patients admitted after elective surgery suffered less often from frailty as defined as CFS ( $28 \%$ vs $46 \%$; $p<0.001$ ), evidenced lower SOFA scores ( $4 \pm 5$ vs $7 \pm 7$; $p<$ 0.001 ). Presence of frailty (CFS $>4$ ) was associated with significantly increased mortality both in elective surgery patients ( $7 \%$ vs $12 \% ; \mathrm{p}=0.01$ ), in acute surgery ( $7 \%$ vs $12 \%$; $\mathrm{p}=0.02$ ).

Conclusions: VIPs admitted to ICU after elective surgery evidenced favorable outcome over patients after acute surgery even after correction for relevant confounders. Frailty might be used to guide clinicians in risk stratification in both patients admitted after elective and acute surgery.

Trial registration: NCT03134807. Registered 1st May 2017.

(C) 2019 Elsevier Inc. All rights reserved.

\section{Introduction}

Patients 80 years and older are admitted to the intensive care unit (ICU) for various reasons. However, patients admitted electively after planned surgery differ from patients who are admitted acutely [1]. Elective admission to ICU has been associated with favorable outcome in the elderly compared to acute patients and it is questionable if these patient sub-groups can be compared with regard to outcomes and risk prediction [1-4].

Mortality of such very old intensive Patients (VIP) admitted to an ICU remains high and post-ICU morbidity causes relevant health costs and leads to human suffering [5]. Further, due to cost pressures on health systems, the question which patients should receive maximal therapy and which patients might benefit primarily from conservative medical therapy arose [6,7]. In one randomized controlled trial, systematic admission to ICU even failed to improve outcomes at 6 -month in patients 75 years and older [8].

Several clinical scores are available to guide clinicians in the intensive care setting. Currently, the most commonly used and most thoroughly tested models are the Sequential Organ Failure Assessment score (SOFA), the Acute Physiology And Chronic Health Evaluation II (APACHE II) and Simplified Acute Physiology Score 2 (SAPS2) score [9-11]. Recently, the Clinical Frailty Scale (CFS), assessing frailty through a simple clinical assessment, has been successfully used to risk-stratify elderly patients $[5,12]$.

Patients admitted after elective surgery versus after acute surgery might differ significantly with regards to characteristics, outcomes and predictors of outcomes. We therefore aimed to compare admitted after elective surgery or intervention versus after acute surgery or intervention in a large, multinational collective of VIPs admitted to an ICU with regards to outcome and predictors of mortality with special emphasis on frailty.

\section{Methods}

\subsection{Study subjects}

VIP1 is a prospective multicenter study, registered on ClinicalTrials. gov (ID: NTC03134807). These patients were already investigated in another context and methods and patients have been described in previous publications $[5,12,13]$. In summary, each participating ICU could either include consecutive patients during a three-month period or the first 20 consecutive patients fulfilling the inclusion criteria (all patients aged 80 years or older admitted to a participating ICU). Data were collected between October 2016 and February 2017. Patients with prior elective surgery or intervention before admission to ICU were considered elective, all others acute. Patients after elective surgery or intervention were admitted for post-operative management including troubleshooting of perioperative complications.

In this study all patients with reported age, sex, frailty score and SOFA score and data on ICU mortality were included. Data on 30-day mortality was available in 820 elective and in 3830 acute patients.

\subsection{Statistical analysis}

Continuous data points are expressed as median \pm interquartile range (IQR). Differences between independent groups were calculated using Mann-Whitney $U$ test for non-paired data and Wilcoxon test for paired data. Categorical data are expressed as numbers (percentage). Chi-square test was applied to calculate differences between groups and McNemar's test for paired data. Univariate and multivariable logistic regression analysis was performed to assess associations with mortality and calculate odds ratios (OR). For the multivariable regression model, confounders with a p-value $<0.10$ in the univariate analysis were included. Elimination criterion was a p-value of $>0.10$. Predictiveness was evaluated calculating area under the curve (AUC) and an optimal cut-off was calculated by means of the Youden Index. A p-value of $<0.05$ was considered statistically significant.

\subsection{Matched-paired analysis}

296 patients admitted after acute surgery or intervention were matched for age, sex, frailty and SOFA score (perfect-match) to 296 patients admitted after elective surgery or intervention. Paired analysis was applied as described above. SPSS version 22.0 (IBM, USA) and MedCalc Statistical Software version 18.6 (MedCalc Software bvba, Ostend, Belgium; http://www.medcalc.org; 2018) were used for all statistical analyses.

\section{Results}

\subsection{Study population}

Admission diagnoses and baseline characteristics are presented in Table 1. Compared to patients admitted after acute surgery or intervention, patients admitted after elective surgery or intervention were younger ( $83 \pm 5$ vs $84 \pm 5$ years; $\mathrm{p}<0.001)$, suffered less often from frailty as defined as CFS ( $28 \%$ vs $46 \%$; $p<0.001$ ), evidenced lower SOFA scores ( 4 \pm 5 vs $7 \pm 7 ; \mathrm{p}<0.001)$ and had a shorter ICU length of stay ( $1.2 \pm 2$ vs $2.1 \pm 5.4$ days; $\mathrm{p}<0.001)$. In patients admitted after elective surgery, both treatment withdrawal (5\% vs $15 \%$; $\mathrm{p}<0.001$ ) and withholding ( $2 \%$ vs $8 \% ; p<0.001$ ) were less frequent. Patients admitted after elective 
Table 1

Baseline characteristics in the overall cohort

\begin{tabular}{|c|c|c|c|c|c|}
\hline & $\begin{array}{l}\text { Acute } \\
\text { medical }\end{array}$ & Trauma & $\begin{array}{l}\text { Acute } \\
\text { surgery }\end{array}$ & $\begin{array}{l}\text { Elective } \\
\text { surgery }\end{array}$ & p-value \\
\hline $\mathrm{n}=$ & 3484 & 255 & 402 & 922 & \\
\hline \multicolumn{6}{|l|}{ Age } \\
\hline Median (IQR) & $\begin{array}{l}84 \\
(81-86)\end{array}$ & $\begin{array}{l}84 \\
(81-86)\end{array}$ & $\begin{array}{l}84 \\
(82-87)\end{array}$ & $\begin{array}{l}83 \\
(81-86)\end{array}$ & $<0.001$ \\
\hline \multicolumn{6}{|l|}{ Frailty score } \\
\hline Median (IQR) & $4(3-6)$ & $4(3-6)$ & $4(3-5)$ & $4(3-5)$ & $<0.001$ \\
\hline \multicolumn{6}{|l|}{ SOFA score } \\
\hline Median (IQR) & $7(4-11)$ & $7(4-11)$ & $7(4-11)$ & $4(2-7)$ & $<0.001$ \\
\hline \multicolumn{6}{|l|}{ ICU length of stay } \\
\hline Median (IQR) & $\begin{array}{l}2.9 \\
(1.1-6.6)\end{array}$ & $\begin{array}{l}2.9 \\
(1.1-6.6)\end{array}$ & $\begin{array}{l}2.1 \\
(1.0-6.0)\end{array}$ & $\begin{array}{l}1.2 \\
(0.9-2.9)\end{array}$ & $<0.001$ \\
\hline Female sex & $\begin{array}{l}1686 \\
(48 \%)\end{array}$ & $108(42 \%)$ & $212(47 \%)$ & $414(45 \%)$ & 0.01 \\
\hline $\begin{array}{l}\text { Treatment } \\
\text { withdrawn }\end{array}$ & $983(28 \%)$ & $68(27 \%)$ & $59(15 \%)$ & $43(5 \%)$ & $<0.001$ \\
\hline Treatment withhold & $515(15)$ & $51(20 \%)$ & $31(8 \%)$ & $15(2 \%)$ & $<0.001$ \\
\hline NIV & $981(28 \%)$ & $32(13 \%)$ & $62(15 \%)$ & $86(9 \%)$ & 0.002 \\
\hline Intubation & $\begin{array}{l}1753 \\
(50 \%)\end{array}$ & $167(65 \%)$ & $213(53 \%)$ & $412(45 \%)$ & 0.006 \\
\hline $\begin{array}{l}\text { Renal replacement } \\
\text { therapy }\end{array}$ & $383(11 \%)$ & $10(4 \%)$ & $36(9 \%)$ & $40(4 \%)$ & 0.002 \\
\hline Vasoactive drugs & $\begin{array}{l}1925 \\
(55 \%)\end{array}$ & $129(51 \%)$ & $250(62 \%)$ & $326(35 \%)$ & $<0.001$ \\
\hline
\end{tabular}

IQR - inter-quartile range; SOFA - sequential organ failure assessment score; ICU - intensive care uni; NIV - non-invasive ventilation.

surgery less often needed renal replacement therapy 4\% vs 9\%; ( $\mathrm{p}<$ $0.001)$, vasoactive drugs $35 \%$ vs $62 \%(\mathrm{p}<0.001)$ and were intubated less often ( $45 \%$ vs $53 \%$; $p<0.001$ ). In patients after acute surgery, 274 of 402 patients were admitted from out-of-hospital.

\subsection{Survival analysis}

Compared to patients admitted after acute surgery both ICU (3\% vs $14 \%$; $<0.001$ ) and 30 -day mortality ( $8 \%$ vs $26 \%$; p < 0.001 ) were lower in patients admitted after elective surgery, even after correction for frailty, age, sex and SOFA score (30-day-mortality; OR 0.39 95\%CI $0.24-0.63 ; \mathrm{p}<0.001$ ). Again, after exclusion of patients in whom treatment was withdrawn or withhold, patients admitted after elective surgery evidenced lower intra-ICU (1\% vs $7 \%$; p < 0.001) and 30-day mortality ( $6 \%$ vs $13 \%$; $<$ 0.001) compared to patients admitted after acute surgery.

Predictors of 30-day-mortality are given in Table 2. Presence of frailty (CFS $>4$ ) was associated with significantly increased mortality both in patients admitted after elective surgery (7\% vs $12 \%$; OR 1.96 $95 \%$ CI $1.17-3.27 ; \mathrm{p}=0.01$ ), in patients after acute surgery ( $2 \%$ vs $34 \%$; OR $1.8295 \%$ CI $1.15-2.89 ; \mathrm{p}=0.01$ ) as well in all acute (36\% vs $49 \%$; OR 1.70 95\%CI 1.50-1.94; p < 0.001) patients. Frailty was moderately

Table 2

Association of relevant factors with 30-day mortality in elective surgery and acute surgery patients.

\begin{tabular}{lllllllll}
\hline & \multicolumn{3}{l}{ Univariate } & & \multicolumn{2}{l}{ Multivariate } \\
\cline { 2 - 3 } A - acute surgery & HR & $95 \% \mathrm{CI}$ & $\mathrm{p}$-value & & HR & $95 \% \mathrm{CI}$ & p-value \\
\hline Age & 1.05 & $0.99-1.11$ & 0.13 & & & \\
Frailty score & 1.21 & $1.05-1.39$ & 0.007 & & 1.26 & $1.09-1.46$ & 0.002 \\
SOFA score & 1.14 & $1.08-1.20$ & $<0.001$ & & 1.15 & $1.09-1.21$ & $<0.001$ \\
Female sex & 1.28 & $0.81-2.03$ & 0.30 & & & \\
B - elective surgery & HR & $95 \% \mathrm{CI}$ & $\mathrm{p}$-value & HR & $95 \% \mathrm{CI}$ & p-value \\
\hline Age & 1.04 & $0.97-1.11$ & 0.30 & & & \\
Frailty score & 1.33 & $1.13-1.56$ & 0.001 & & 1.32 & $1.12-1.55$ & 0.001 \\
SOFA score & 1.15 & $1.09-1.22$ & $<0.001$ & & 1.15 & $1.08-1.22$ & $<0.001$ \\
Female sex & 1.04 & $0.63-1.71$ & 0.89 & & & \\
\hline
\end{tabular}

SOFA - sequential organ failure assessment score.
Table 3

Baseline characteristics in the matched-paired cohort ( $n=655$ patients for each group).

\begin{tabular}{llll}
\hline & Elective surgery & Acute surgery & p-value \\
\hline $\begin{array}{l}\mathrm{n}= \\
\text { Age }\end{array}$ & 296 & 296 & \\
$\quad \begin{array}{l}\text { Median (IQR) } \\
\text { Frailty score } \\
\quad \text { Median (IQR) }\end{array}$ & $83(81-86)$ & $83(81-86)$ & $\mathrm{n} / \mathrm{a}$ \\
$\begin{array}{l}\text { SOFA score } \\
\text { Median (IQR) }\end{array}$ & $4(3-5)$ & $4(3-5)$ & $\mathrm{n} / \mathrm{a}$ \\
ICU length of stay & & & \\
$\quad$ Median (IQR) & $6(3-10)$ & $6(3-10)$ & $\mathrm{n} / \mathrm{a}$ \\
$\quad$ Female sex & $1.5(1.00-2.00)$ & $2.00(0.93-5.39)$ & $<0.001$ \\
$\quad$ ICU death & $148(50 \%)$ & $148(50 \%)$ & $\mathrm{n} / \mathrm{a}$ \\
$\quad$ 30-day death & $14(5 \%)$ & $29(10 \%)$ & \\
$\quad \begin{array}{l}\text { Treatment withdrawn } \\
\text { Treatment withhold }\end{array}$ & $28(10 \%)$ & $60(20 \%)$ & $<0.01$ \\
$\quad$ NIV & $14(1 \%)$ & $19(6 \%)$ & $<0.01$ \\
Intubation & $34(12 \%)$ & $37(13 \%)$ & 0.11 \\
$\quad$ Renal replacement therapy & $15(5 \%)$ & $48(16 \%)$ & 0.21 \\
$\quad$ Vasoactive drugs & $133(45 \%)$ & $138(47 \%)$ & 0.15 \\
\hline
\end{tabular}

IQR - inter-quartile range; SOFA - sequential organ failure assessment score; ICU - intensive care unit; NIV - non-invasive ventilation.

predictive for survival at one month (AUC 0.61), an optimal cut-off was exactly at the frailty level of $\leq 4$ points.

In patients admitted after acute surgery, patients admitted from outof-hospital evidenced worse outcome both intra ICU (20\% vs $11 \%$; p = 0.01 ) and at one month (34\% vs $23 \% ; \mathrm{p}=0.02$ ).

\subsection{Matched-pair analysis}

In the two cohorts ( $\mathrm{n}=296$ each from patients admitted after elective surgery versus patients after acute surgery, Table 3) matched for age, gender, frailty and SOFA score, there both ICU mortality (mean difference 5.07\%; 9.37-0.76\%; $p=0.03$ ) and 30-day mortality (mean difference $10.12 \%$; 3.58-16.65\%; $\mathrm{p}<0.01$ ) was lower in patients admitted after elective surgery.

\section{Discussion}

Here we have shown that in patients 80 years and older admitted to ICU, compared to patients admitted after acute surgery or intervention [1] patients admitted after elective surgery or intervention were clinically less sick, younger and less frail as assessed by CFS, [2] even after correction for relevant confounders and in a matched-pair analysis, patients admitted after elective surgery had a shorter ICU length of stay and lower mortality. Further, [3] frailty assessed by CFS was associated with 30-day mortality both in patients admitted after elective and acute surgery.

A growing proportion of VIP is admitted to ICUs and how to risk stratify these patients is of relevance but unclear [14,15]. In our study, patients admitted electively after surgery evidenced better prognosis compared to patients admitted after acute surgery even after correction for age, frailty and organ failure at admission as assessed by CFS and SOFA score, respectively. This is in accordance to studies showing elective ICU admission after surgery being associated with better outcome [1]. Still, compared to patients from European Surgical Outcome Study (EuSOS), mortality in this cohort was higher but seems in line as patients in this cohorts were older and all of them admitted to ICU compared to only $8 \%$ in EuSOS [16]. Of note, differences in comorbidities, known to be associated with outcome, were not systematically reported in this study and might influence the outcome [17]. Parameters assessing dynamics of disease course such as lactate clearance might improve our ability to predict risk of death $[18,19]$. Still, frailty, a condition characterized by deteriorated physiologic reserves and vulnerability to high morbidity due to falls, cognitive decline and hence need for special care, might add insight over biomarkers and intensive care 
scores, which were not specifically developed for VIPs [20,21]. In our study, frailty was assessed by CSF, which has successfully been tested against other tools [22]. Other methods to measure frailty such as (modified) frailty index and hospital frailty risk score were proposed, but not available in this study [23-25]. Still, compared to CFS, these scores primarily assess comorbidities and deviate from the multidimensional frailty concept [26]. Multidimensional score models including frailty might help for better risk prediction: in a study of 275 patients aged 65 years or more undergoing intermediate or high-risk elective surgery, a multidimensional frailty score model (composed of the Charlson Comorbidity Index, dependence in activities of daily living, dementia, risk of delirium, short mid-arm circumference and malnutrition) predicted mortality rates more accurately than the ASA classification [27].

In patients admitted after elective surgery, frailty was associated with higher mortality. We therefore think that before elective surgery VIPs should undergo structured frailty screening. The indication for surgery should undergo rigorous examination if a patient is deemed frail. In VIPs before any elective intervention modifiable risk factors should be reduced. Studies investigating effects of specific measures tailored to minimize the effect of frailty on mortality are warranted [28,29]. Inclusion of geriatric consultancy has proven valuable in other areas of medicine. Studies have documented that for post-operative elderly patients, mainly after hip fracture, geriatric unit admission offers a benefit as compared to surgical unit admission: In Boddaert et al.'s study, postoperative admission to a dedicated geriatric unit reduced both readmission rate ( $14 \%$ versus $29 \%, \mathrm{P}=0.007$ ) and 6 -month mortality (15\% versus $24 \%, \mathrm{P}=0.04$ ). After adjustment for comorbidities, risk ratio of death at 6 months was $0.43(95 \% \mathrm{CI} 0.25$ to $0.73, \mathrm{P}=0.002)$ [30]. Of note, frailty might specifically result in an inability to tolerate or survive perioperative adverse events. Of note, in our study, in elective patients, frailty assessed by CFS was associated with increased onemonth mortality, but not with ICU mortality (data not shown). Frailty might specifically be suited to predict longer-term mortality. In this regard the recently started VIP2 study (NCT03370692) will bring further evidence.

Admissions of VIPs to an ICU bring up both economic and ethical issues [31]. In our study patients admitted acutely evidenced high onemonth-mortality. Costs of VIPs admitted to ICUs were previously shown to be high [6,32]. Further, relevant proportion of surviving VIPs might suffer from high morbidity, although other studies found comparable levels of quality of life to matched non-ICU patients [33-35]. Therefore, a thorough pre-admission assessment is necessary not only in elective but also in acutely admitted VIPs. Therapy goals and possible restrictions should be formulated and communicated early [36,37]. Especially in VIPs an "intensive care trial" of 24 to $72 \mathrm{~h}$ duration should be undertaken. During this time frailty should be assessed and realistic treatment goals in consent with patients and their relatives formulated and critically evaluated [7,38-40]. For these "intensive care trials" in VIPs the concept of "geriatric ICU" with intensive care medicine specialists as well as geriatric specialists is intriguing. Once a "curative" approach is established, geriatric rehabilitation could be planned to reduce long-term morbidity [36].

\subsection{Strengths and limitations}

In our study detailed information about the type of surgery was unavailable. Further, no information in acute or elective patients about a possible delay between decision for surgery/ICU admission and actual surgery/admission in ICU was collected. No information about an early rehabilitation program post-surgery contributing to low one-month mortality was available for analysis. No information about perioperative complications was available. However, strength is that an analysis of a very large, multicenter, multinational cohort with prospectively collected data was available in VIPs.

\section{Conclusion}

VIPs admitted to ICU after elective surgery were younger and clinically less severley ill, resulting in a more favorable outcome compared to patients admitted after acute surgery, even after correction for relevant confounders. Frailty might be used to guide clinicians in risk stratification in both patients admitted after elective and acute surgery.

Supplementary data to this article can be found online at https://doi. org/10.1016/j.jcrc.2019.04.020.

\section{Competing interests}

The authors declare that they have no competing interests.

\section{Author contributions}

BW and CJ analyzed the data and wrote the first draft of the manuscript. HF and BG and DL and IS contributed to statistical analysis and improved the paper. JM and $\mathrm{MK}$ and $\mathrm{AB}$ and $\mathrm{AM}$ and $\mathrm{FA}$ and $\mathrm{AA}$ and BG and MC and SC and LF and JF and ML and BM and RM and SO and CÖ and BP and WS and AV and CW and TZ gave guidance and improved the paper. All authors read and approved the final manuscript.

\section{Funding}

No (industry) sponsorship has been received for this investigatorinitiated study.

\section{Ethics Approval and consent to participate}

A study protocol was provided to participating centers. Every participating center obtained ethics approval according to local legislation. A copy of the ethics approval was sent to the study coordinator before start of the study.

\section{Consent for publication}

Written informed consent was obtained of all included subjects.

\section{Availability of data and materials}

All data relevant for this study will be given by the authors upon specific request.

\section{Acknowledgements}

VIP1 study contributors: René Schmutz, B5, Hospital of St. John of God Vienna, Austria; Franz Wimmer, Interne Intensiv, Kardinal Schwarzenberg'sches Krankenhaus, Austria; Philipp Eller, Intensivstation der Univ.-Klinik für Innere Medizin, Medical University Graz, Austria; Michael Joannidis, MICU, University Hospital Innsbruck, Austria; Pieter De Buysscher, Department of Intensive Care, AZ SintLucas Ghent, Belgium; Nikolaas De Neve, Department of Intensive Care, O.L.Vrouwhospital Aalst, Belgium; Sandra Oeyen, Department of Intensive Care, Ghent University Hospital, Belgium; Walter Swinnen, Department of Intensive Care Medicine, AZ Sint-Blasius Dendermonde, Belgium; Bernardo Bollen Pinto, Peri-interventional Intermidate Care (SINPI), Geneva University Hospitals, Switzerland; Paul Abraham, Adult Intensive Care (SIA), Geneva University Hospitals, Switzerland; Leila Hergafi, Service des Soins intensifs, Hôpital fribourgeois, Fribourg, Switzerland; Joerg C. Schefold, Universitätsklinik für Intensivmedizin, Inselspital, Bern University Hospital, University of Bern, Switzerland; Ewelina Biskup, Medical ICU, University Hospital Basel, Switzerland; Petr Piza, KARIP, IKEM, Czech Republic.; Ioannis Taliadoros, CY001, Nicosia General Hospital, Cyprus; Jesper Fjølner, ITA, Randers Regional Hospital, Denmark; Nilanjan Dey, Intensiv Herning, Regions Hospital 
Herning, Denmark; Christoffer Sølling, I-25, Regionshospital Viborg, Denmark; Bodil Steen Rasmussen, ICU, Aalborg University Hospital, Denmark; Steffen Christensen, OPI Ost, Aarhus University Hospital Skejby, Denmark; Xavier Forceville, Réanimation médico chirurgical, Centre Hospitalier de Meaux, France; Guillaume Besch, Département d'Anesthésie Réanimation Chirurgicale, Centre Hospitalier Régional Universtaire de Besançon, France; Herve Mentec, Service de Réanimation Polyvalente, Centre Hospitalier Victor Dupouy Argenteuil, France; Philippe Michel, Réanimation médico-chirurgicale, CH Carnelle - Portes de l'Oise, France; Philippe Mateu, Réanimation Polyvalente, $\mathrm{CH}$ de Charleville-Mézières, France; Philippe Michel, Réanimation médicochirurgicale, $\mathrm{CH}$ René Dubos, France; Lucie Vettoretti, Réanimation Médicale, CHRU de Besançon, France; Jeremy Bourenne, Reanimation des Urgences et Médicale, CHU Marseille - Timone, France; Nathalie MARIN, reanimation médicale, hopital cochin, France; Max Guillot, Réanimation médicale, Hôpital de Hautepierre, France; Naida Aissaoui, Réanimation médicale, hopital européen georges pompidou, France; Cyril Goulenok, Réanimation Médicale, Hopital Privé Jacques CARTIER, France; Nathalie Thieulot-Rolin, Intensive care medicine department, Hospital Marc Jacquet 77000 Melun, France; Jonathan Messika, Réanimation Médico-Chirurgicale, Louis Mourier, France; Lionel Lamhaut, Polyvalente adult ICU, Necker (APHP), France; Bertrand Guidet, Réanimation médicale, Saint Antoine, France; Cyril Charron, Medicalsurgical ICU, University Hospital Ambroise Paré, de Paris BoulogneBillancourt, France, France; Alexander Lauten, 1) Department of Cardiology, 2) DZHK Berlin partner side, Charité Universitaetsmedizin Berlin, Germany; Anna Lena Sacher, Department of Anesthesiology, Charité Universitaetsmedizin Berlin, Germany; Thorsten Brenner, Department of Anesthesiology, Heidelberg University Hospital, Germany; Marcus Franz, Department of Internal Medicine, Jena University Hospital, Friedrich-Schiller University, Germany; Frank Bloos, Department of Anesthesiology, Jena University Hospital, Friedrich-Schiller University, Germany; Henning Ebelt, Department for Medicine II, Catholic Hospital "St. Johann Nepomuk", Germany; Stefan J Schaller, Department of Anesthesiology, Klinikum rechts der Isar, Technical University of Munich, Munich, Germany; Kristina Fuest, Department of Anesthesiology, Klinikum rechts der Isar, Technical University of Munich, Munich, Germany, Germany; Christian Rabe, Department Of Clinical Toxicology, Klinikum rechts der Isar, Technical University of Munich, Munich, Germany, Germany; Thorben Dieck, Department of Anaesthesiology and Intensive Care, Medical School Hospital Hannover, Germany; Stephan Steiner, Department of Cardiology, Pneumology and Intensive Care, St. Vincenz Krankenhaus Limburg, Germany; Tobias Graf, Department of Cardiology, University Heart Center Luebeck, Germany; Amir M Nia, Division of Cardiology and Intensive Care, University Hospital Düsseldorf, Heinrich-Heine University, Germany; Christian Jung, Division of Cardiology and Intensive Care, University Hospital Düsseldorf, Heinrich-Heine University, Germany; Rolf Alexander Janosi, Department of Cardiology and Vascular Diseases, University Hospital Essen, Germany; Patrick Meybohm of the Department of Anaesthesiology, Intensive Care Medicine and Pain Therapy, Frankfurt University Hospital, Frankfurt, Germany; Philipp Simon, Department of Anaesthesiology and ICM, University Hospital of Leipzig, Germany; Stefan Utzolino, Department of General and Visceral Surgery, Universitätsklinikum Freiburg, Germany; Tim Rahmel, Department of Anaesthesiology, Intensive Care Medicine, University Hospital Knappschaftskrankenhaus Bochum, Germany; Eberhard Barth, Department of Anaesthesiology, University of Ulm, Germany; Christian Jung, University Hospital Düsseldorf, Heinrich-Heine-University Düsseldorf, Medical Faculty, Division of Cardiology, Pulmonology and Vascular Medicine, Düsseldorf, Germany, Germany; Michael Schuster, Department of Anaesthesiology, University Hospital Mainz, Germany; Zoi Aidoni, ICU, UGHT AHEPA, Greece; Stavros Aloizos, ICU, Army Share Fund Hospital, Athens, Greece; Polychronis Tasioudis, ICU, G. Gennimatas hospital of Thessaloniki, Greece; Kleri Lampiri, ICU, General Hospital Of Kavala, Greece; Vasiliki Zisopoulou, ICU1, General Hospital Of Larissa, Greece;
Ifigenia Ravani, ICU, General hospital of Patras, Greece; Eumorfia Pagaki, ICU, General hospital of Trikala, Greece; Angela Antoniou, ICU, Volos General Hospital, Greece; Theodoros A. Katsoulas, ICU, "Ag Anargyroi” General Hospital, Greece; Aikaterini Kounougeri, ICU, Konstantopouleion General Hospital, Athens, Greece; George Marinakis, ICU, "Korgialenio-Benakio" G. Hospital of Athens, Greece; Fotios Tsimpoukas, ICU, Lamia General Hospital, Greece; Anastasia Spyropoulou, ICU, Panarkadian General Hospital of Tripolis, Greece; Paris Zygoulis, General ICU, University hospital of Larisa, Greece; Aikaterini Kyparissi, ICU, "HIPPOCRATEIO” General Hospital of Athens, Greece; Manish Gupta, MICU, MAX SUPER SPECIALTY HOSPITAL, Vaishali, India; Mohan Gurjar, Department of Critical Care Medicine, Sanjay Gandhi Postgraduate Institute of Medical Sciences, India; Ismail M Maji, MICU, St Johns Medical Colleg Hospital, Bangaluri, India; Ivan Hayes, CUH GICU, Cork University Hospital, Ireland; Brian Marsh, Department of Critical Care Medicine, Mater Misericordiae University Hospital, Ireland; Yvelynne Kelly, General ICU, St. Jamess Hospital, Ireland; Andrew Westbrook, ICU, St. Vincents University Hospital, Ireland; Gerry Fitzpatrick, Tallaght intensive Care, Tallaght Hospital, Ireland; Darshana Maheshwari, UHG ICU, University hospital galway, Ireland; Catherine Motherway, ICU, University Hospital limerick, Ireland; Giovanni Negri, Rianimazione, A.S.S.T. Ovest Milanese - Presidio Di Magenta - Ospedale G. Fornaroli (Magenta), Italy; Savino Spadaro, Unità di Terapia Intensiva del Servizio di Anestesia, Azienda Ospedaliera Universitaria Sant Anna (Ferrara), Italy; Giuseppe Nattino, Rianimazione generale, ASST Lecco Ospedale A.Manzoni (Lecco), Italy; Matteo Pedeferri, Rianimazione, AO della Provincia di Lecco - Presidio Ospedaliero S.Leopoldo Mandic, Merate, Italy; Annalisa Boscolo, Giustiniani I e II (Istar), Azienda Ospedaliera di Padova (Padova), Italy; Simona Rossi, Servizio Anestesia Rianimazione, Azienda Ospedaliera G.Salvini - Presidio Ospedaliero di Rho, Italy; Giuseppe Calicchio, Centro di Rianimazione, Azienda Ospedaliera Universitaria San Giovanni di Dio e Ruggi d'Aragona, Italy; Lucia Cubattoli, Rianimazione Generale, Azienda Ospedaliera Universitaria Senese (Siena), Italy; Gabriella Di Lascio, Terapia Intensiva di Emergenza, Azienda Ospedaliero Universitaria Careggi (Firenze), Italy; Maria Barbagallo, UO 2 Anestesia Rianimazione Terapia Intensiva, Azienda Ospedaliero-Universitaria di Parma (Parma), Italy; Francesco Berruto, rianimazione, Ospedale E. Agnelli (Pinerolo), Italy; Daniela Codazzi, Unità Terapia Intensiva, Fondazione IRCCS Istituto Nazionale dei Tumori (Milano), Italy; Andrea Bottazzi, Rianimazione 2, Fondazione IRCCS Policlinico S.Matteo (Pavia), Italy; Paolo Fumagalli, Rianimazione 1, Fondazione Policlinico San Matteo (Pavia), Italy; Giancarlo Negro, Anestesia e Rianimazione 1, Ospedale Francesco Ferrari (Casarano), Italy; Giuseppe Lupi, Servizio Anestesia e Rianimazione, Ospedale Maggiore (Cremona), Italy; Flavia Savelli, Anestesia e Rianimazione TI 2, Ospedale Maurizio Bufalini (Cesena), Italy; Giuseppe A. Vulcano, Terapia Intensiva, Ospedale Civile Nicola Giannettasio (Rossano), Italy; Roberto Fumagalli, Anestesia e Rianimazione 1, Ospedale Niguarda Ca' Granda (Milano), Italy; Andrea Marudi, Rianimazione Neurorianimazione, Nuovo Ospedale Civile Sant Agostino Estense (Modena), Italy; Ugo Lefons, Terapia intensiva, Ospedale Alta Val d'Elsa (Poggibonsi), Italy; Rita Lembo, Rianimazione generale, Ospedale Castelli di Verbania (Verbania), Italy; Maria Babini, Servizio Anestesia e Rianimazione, Ospedale Civile Lugo (Lugo), Italy; Alessandra Paggioro, Struttura Semplice di Rianimazione e Terapia Intensiva, Ospedale degli Infermi di Biella - ASL BI (Biella), Italy; Vieri Parrini, Anestesia e Rianimazione, Ospedale del Mugello (Borgo San Lorenzo), Italy; Maria Zaccaria, Rianimazione e Terapia Intensiva, Ospedale di Ciriè (Torino), Italy; Stefano Clementi, terapia intensiva polivalente, Ospedale di Sesto San Giovanni (Sesto San Giovanni), Italy; Carmelo Gigliuto, Rianimazione, Ospedale di Vigevano - Azienda Ospedaliera della Provincia di Pavia (Vigevano), Italy; Francesca Facondini, Reparto di Rianimazione e Terapia Intensiva, Ospedale Infermi (Rimini), Italy; Simonetta Pastorini, Servizio Anestesia-Rianimazione, Ospedale P. Cosma-AUSL 15 Alta padovana (Camposampiero), Italy; Susanna Munaron, Unità di Terapia Intensiva, Ospedale San Giacomo 
(Castelfranco Veneto), Italy; Italo Calamai, Rianimazione, Ospedale San Giuseppe (Empoli), Italy; Anna Bocchi, Terapia Intensiva, Ospedale San Luca (Trecenta), Italy; Adele Adorni, Unità di Terapia Intensiva Rianimatoria, Ospedale Valduce (Como), Italy; Maria Grazia Bocci, Centro di Rianimazione, Policlinico Agostino Gemelli (Roma), Italy; Andrea Cortegiani, Unità di Terapia Intensiva Polivalente, Policlinico P. Giaccone. University of Palermo, Italy; Tiziana Casalicchio, Terapia Intensiva, Ospedale San Giovanni Bosco (Torino), Italy; Serena Mellea, Unità di Terapia Intensiva, Ospedale Santa Maria della Misericordia (Perugia), Italy; Elia Graziani, Unità Operativa Anestesia e Rianimazione, Santa Maria delle Croci (Ravenna), Italy; Massimo Barattini, Rianimazione, Ospedale Santa Maria Nuova (Firenze), Italy; Elisabetta Brizio, Servizio di Rianimazione, Ospedale SS Annunziata, Italy; Maurizio Rossi, UO Anestesia e Rianimazione, Azienda Ospedaliera Sant'Anna Como - Presidio di Menaggio, Italy; Michael Hahn, ICU, Haugesund hospital, Norway; Hans Flaatten, General ICU, Haukeland University Hospital, Norway; Nicolai Kemmerer, ICU, Kongsberg hospital, Norway; Hans Frank Strietzel, ICU, Kristiansund Hospital, Norway; Knut Dybwik, ICU, Nordlandssykehuset Bodo, Norway; Terje Legernaes, ICU, Hamar hospital, Norway; Pål Klepstad, Dept Intensive Care Medicine, St Olavs University Hospital, Norway; Even Braut Olaussen, ICU, Stavanger University Hospital, Norway; Knut Inge Olsen, ICU, Namsos Hospital, Norway; Ole Marius Brresen, ICU, Telemark Hospital, Skien, Norway; Geir Bjorsvik, ICU, University Hospital Tromso, Norway; Finn H. Andersen, ICU, Ålesund hospital, Norway; Sameer Maini, Medical ICU, Aalesund Hospital, Norway; Lutz Fehrle, ICU, Molde hospital, Norway; Miroslaw Czuczwar, ICU, First Public Teaching Hospital in Lublin, Poland; Pawel Krawczyk, ICU, University Hospital in Krakow, Poland; Mirosław Ziętkiewicz, Respiratory and Thoracic Surgical ICU, John Paul II Hospital in Krakow, Poland; Łukasz R. Nowak, Department of Anaesthesiology and Intensive Care, Maria Sklodowska-Curie Memorial Institute of Oncology Krakow Branch, Poland; Katarzyna Kotfis, Department of Anaesthesia, Intensive Care and Acute Poisonings, Pomeranian Medical University, Teaching Hospital No.2, Poland; Katarzyna Cwyl, ICU, RCZ in Lublin, Poland; Ryszard Gajdosz, Department of Anaesthesiology and Intensive Care, Scanmed St. Raphael Hospital in Kraków, Poland; Jowita Biernawska, Department of Anaesthesiology and Intensive Care, Pomeranian Medical University, Teaching Hospital No. 1, Poland; Romuald Bohatyrewicz, Department of Anaesthesiology and Intensive Care, Pomeranian Medical University, Teaching Hospital No. 1, Poland; Ryszard Gawda, Department of Anaesthesiology and Intensive Care, University Hospital in Opole, Poland; Paweł Grudzień, ICU, Edward Szczeklik Specialist Hospital in Tarnów, Poland; Paweł Nasiłowski, Department of Anaesthesiology and Intensive Care, Gabriel Narutowicz Specialist Hospital in Kraków, Poland; Natalia Popek, Department of Anaesthesiology and Intensive Care, Stefan Żeromski Specialist Hospital in Kraków, Poland; Waldemar Cyrankiewicz, Department of Anaesthesiology and Intensive Care, Antoni Jurasz University Hospital No. 1 in Bydgoszcz, Poland; Katarzyna Wawrzyniak, Department of Anaesthesiology and Intensive Care, Antoni Jurasz University Hospital No. 1 in Bydgoszcz, Poland; Marek Wnuk, Department of Anaesthesiology and Intensive Care, John Paul II Memorial Hospital in Bełchatów, Poland; Dariusz Maciejewski, Department of Anaesthesiology and Intensive Care, Provincial hospital in Bielsko-Biała, Poland; Dorota Studzińska, Department of Anaesthesiology and Intensive Care, St. John Grande Hospital, Poland; Maciej Żukowski, Department of Anaesthesiology, Intensive Care and Acute Poisoning, Pomeranian Medical University, Teaching Hospital No. 2 in Szczecin, Poland; Szymon Bernas, Department of Anaesthesiology and Intensive Therapy Centre for Artificial Extracorporeal Kidney and Liver Support, Dr. Władysław Biegański Regional Specialist Hospital in Łódź, Poland; Mariusz Piechota, Department of Anaesthesiology and Intensive Therapy Centre for Artificial Extracorporeal Kidney and Liver Support, Dr. Władysław Biegański Regional Specialist Hospital in Łódź, Poland; Centre for Artificial Extracorporeal Kidney and Liver Support, Poland; Wojciech Szczeklik, Department of Intensive Care and Perioperative
Medicine, University Hospital in Kraków, Poland; Ilona Nowak, Department of Intensive Care and Perioperative Medicine, University Hospital in Kraków, Poland; Jakub Fronczek, Department of Intensive Care and Perioperative Medicine, University Hospital in Kraków, Poland; Marta Serwa, Department of Anaesthesiology and Intensive Care, University Hospital and Educational Centre of the Medical University of Łódź, Poland; Waldemar Machała, Department of Anaesthesiology and Intensive Care, University Hospital and Educational Centre of the Medical University of Łódź, Poland; Jan Stefaniak, Department of Anaesthesiology and Intensive Care, University Clinical Centre in Gdańsk, Poland; Maria Wujtewicz, Department of Anaesthesiology and Intensive Care, University Clinical Centre in Gdańsk, Poland; Paweł Maciejewski, Department of Anaesthesiology and Intensive Care, OrthopedicRehabilitation University Hospital in Zakopane, Poland; Małgorzata Szymkowiak, Department of Anaesthesiology and Intensive Care, Józef Struś Hospital in Poznan, Poland; Barbara Adamik, Department of Anaesthesiology and Intensive Care, Wrocław University Hospital, Poland; Nuno Catorze, UCIP, C. H. Médio TEJO, Portugal; Miguel Castelo Branco, Unidade de Cuidados Intensivos, Centro Hospitalar Cova da Beira, EPE, Portugal; Inês Barros, Unidade de Cuidados Intensivos Polivalente, Centro Hospitalar Tondela-Viseu, Portugal; Nelson Barros, Serviço Medicina Intensiva, Centro Hospitalar Trás-os-Montes e Alto Douro, Portugal; Andriy Krystopchuk, Intensive Care and Emergency Department, Centro Hospitalar do Algarve-Hospital de Faro, Portugal; Teresa Honrado, Unidade Cuidados INtensivos Polivalente, Hospital de São João, Portugal; Cristina Sousa, UCI, Hospital da Luz, Portugal; Francisco Munoz, UMI, Hospital do SAMS, Portugal; Marta Rebelo, UCIP, Hospital de Egas Moniz, Portugal; Rui Gomes, UCI, Hospital Garcia de Orta, Portugal; Jorge Nunes, Unidade de Cuidados Intensivos, Hospital Lusiadas Lisboa, Portugal; celeste dias, Neurocritical ICU, Hospital de São João, Portugal; Ana Margarida Fernandes, UCI Neurocríticos, Hospital S. José - CHLC EPE, Portugal; Cristina Petrisor, Anaesthesia and Intensive Care 1, Clinical Emergency County Hospital Cluj, Portugal; Bodolea Constantin, ATI, Municipal Hospital, Portugal; Vladislav Belskiy, Department of Anesthesiology and Intensive Care, Privolzhskiy District Medical Center, Russia; Boris Boskholov, Dept of intensive care, Zhadkevich Clinical Hospital, Russia; Enver Rodriguez, UCI, General Universitario de Castellón, Spain; Sergio Rebollo, ICU, HGU Santa Lucia,Cartagena, Murcia, Spain; Gerardo Aguilar, Unidad de Reanimación - Surgical ICU, Hospital Clínico Universitario de Valencia, Spain; Gaspar Masdeu, Servei Medicina Intensiva, Hospital de Tortosa Verge de la Cinta, Spain; Marián Irazábal Jaimes, Critical Care Unit, Hospital General de Catalunya, Spain; Ángela Prado Mira, Medicina Intensiva, Hospital General Universitario de Albacete, Spain; Maria A. Bodi, General ICU, Hospital Universitari de Tarragona Joan XXIII, Spain; Jesus A. Barea Mendoza, Servicio de Medicina Intensiva, Hospital Universitario 12 de Octubre, Spain; Sonia LópezCuenca, Servicio de Medicina Intensiva y Grandes Quemados, Hospital Universitario de Getafe, Spain; Marcela Homez Guzman, ICU, Hospital Universitario del Henares, Spain; Jesús Rico-Feijoo, Postoperative Critical Care Unit and Reanimation, Hospital Universitario Río Hortega de Valladolid, Spain; Mercedes Ibarz, ICU Hospital Universitario Sagrado Corazon, Hospital Universitario Sagrado Corazon. Barcelona, Spain; Josep Trenado Alvarez, Intensive Care Department. UCI-Semicritics, Hospital Universitario Mutua Terassa, Spain; Rafael Kawati, central ICU, Akademiska sjukhuset, Sweeden; Joakim Sivik, IVA Alingsås Lasarett, Alingsås Lasarett, Sweeden; Jessica Nauska, Intensivvårdsavdelning 31, Blekingesjukhuset Karlskrona, Sweeden; Daniel Smole, IVA, Centralsjukhuset i Karlstad, Sweeden; Fredric Parenmark, IVA, Gävle sjukhus, Sweeden; Johanna Lyrén, Intensivvårdsavdelning, Hudiksvalls sjukhus, Gävleborg, Hudiksvalls sjukhus, Sweeden; Katalin Rockstroh, IVA, Kalmar Länssjukhus, Sweeden; Sara Rydén, Karolinska ICU Huddinge, Karolinska University Hospital Huddinge, Sweeden; Martin Spångfors, Intensiven, Kristianstad, Sweeden; Morten Strinnholm, ICU Kungälvs Hospital, Kungälvs hospital, Sweeden; Sten Walther, Cardiothoracic ICU, Linköping University Hospital, Sweeden; Lina De Geer, ICU, Linköping University Hospital, Sweeden; Peter Nordlund, 
OP/IVA Kliniken, Länssjukhuset Ryhov, Sweeden; Staffan Pålsson, Intensivvårdsavdelningen, Norrtälje, Sweeden; Harald Zetterquist, IVA, Nykopings lasarett, Sweeden; Annika Nilsson, IVA, Ornskoldsvik, Ornskoldsviks hospital, Sweeden; Karin Thiringer, avdelning 227, IVA, Sahlgrenska University Hospital Mölndal, Sweeden; Mårten Jungner, ICU SUS Malmö, Skane University Hospital, Sweeden; Björn Bark, IVA Lund, Skåne University Hospital, Sweeden; Berit Nordling, IVA Sundsvall, Sundsvall, Sweeden; Hans Sköld, ICU, Torsby Sjukhus, Sweeden; Camilla Brorsson, CIP, University Hospital Northern Sweden, Sweeden; Stefan Persson, Intensivvårsdavdelningen USÖ, University hospital Örebro, Sweeden; Anna Bergström, IVA Vrinnevisjukhuset, Vrinnevi hospital, Sweeden; Johan Berkius, IVA Västervikssjukhus, Västervikssjukhus, Sweeden; Johanna Holmström, Intensivvårdsavdelningen Västerås, Västmanlands sjukhus, Västerås, Sweeden; I. van Dijk, Intensive Care, Alrijne Ziekenhuis, The Netherlands; L.E.M. van Lelyveld-Haas, Intensive Care, Diakonessenhuis Utrecht, The Netherlands; D.Ramnarain, Intensive Care, Elisabeth Tweesteden Hospital Tilburg, The Netherlands; Tim Jansen, Intensive Care, HagaZiekenhuis, The Netherlands; Fleur Nooteboom, IC LZR, Laurentius Ziekenhuis, The Netherlands; Peter HJ van der Voort, ICU OLVG, OLVG, The Netherlands; Dylan de Lange, Department of Intensive Care Medicine, UMC Utrecht, The Netherlands; Willem Dieperink, Department of Critical Care, University Medical Center Groningen, The Netherlands; Monique C. de Waard, Intensive Care Adults, VU University Medical Center Amsterdam, The Netherlands; Annemarie GE de Smet, Intensive Care Unit, University Medical Centre, University of Groningen, The Netherlands; Laura Bormans, Intensive Care, Zuyderland Medical Centrer, Heerlen, The Netherlands; Tom Dormans, Intensive Care, Zuyderland Medical Center, Heerlen, The Netherlands; Ged Dempsey, Critical Care Unit, Aintree University Hospital NHS Foundation Trust, UK; Shiju J Mathew, ICU, Alexandra Hospital, UK; Ashok S Raj, ICU, Barts Health NHS Trust, Whipps Cross Hospital, UK; Irina Grecu, ITU/HDU, Basingstoke and North Hampshire Hospital, UK; Jason Cupitt, Critical Care Unit, Blackpool Teaching Hospitals NHS Foundation Trust, UK; Tom Lawton, Critical Care Unit, Bradford Royal Infirmary, UK; Richard Clark, ICU, Central Manchester Foundation Trust, UK; Monica Popescu, ICU, Chelsea and Westminster Foundation Trust, West Middlesex University Hospital, UK; Nick Spittle, ICU, Chesterfield Royal Hospital, UK; Maria Faulkner, ICU, Countess of Chester Hospital NHS Foundation Trust, UK; Amanda Cowton, ICU, Darlington memorial Hospital (CDDFT), UK; Esme Elloway, ICU, Derriford Hospital, UK; Patricia Williams, Critical Care Unit, Dorset County Hospital, UK; Michael Reay, Critical Care Unit, Dudley Group of Hospitals NHSFT, Russells Hall Hospital, UK; Srikanth Chukkambotla, Critical Care Unit, East Lancashire Hospitals NHS Trust, UK; Ravi Kumar, CCU, East Surrey Hospital, UK; Nawaf Al-Subaie, ICU, Espsom and St Helier University Hospitals, UK; Linda Kent, Critical Care Unit, Fairfield General Hospital, UK; Tiina Tamm, ICU, Frimley Health, Wexham Park Hospital, UK; Istvan Kajtor, ICU, Frimley Park Hospital, UK; Karen Burns, ICU, Furness General, UK; Richard Pugh, Critical Care Unit, Glan Clwyd Hospital, UK; Marlies Ostermann, ICU, Guys and St Thomas Hospital, UK; Elisa Kam, ICU, Hillingdon Hospital, UK; Helen Bowyer, Critical Care Centre, Hinchingbrooke Healthcare NHS Trust, UK; Neil Smith, HICU 1\&2, Hull Royal Infirmary, UK; Maie Templeton, Critical Care UNIT, Imperial College Healthcare NHS Trust, UK; Jeremy Henning, ICU2\&3, James Cook Univeristy Hospital, UK; Kelly Goffin, ICU, James Paget University Hospital, UK; Ritoo Kapoor, K\&C ITU, Kent and Canterbury Hospital, UK; Shondipon Laha, CrCU, Lancashire Teaching Hospitals NHS Foundation Trust, UK; Phil Chilton, Critical Care Unit, Leighton Hospital, UK; Waqas Khaliq, ITU/HDU, Lewisham and Greenwich NHS Trust, UK; Alison Crayford, ITU/HDU, Maidstone, UK; Samantha Coetzee, ICU, Medway NHS Foundation Trust, UK; Moira Tait, Adult ICU, Musgrove Park, UK; Wendy Stoker, ICU, Northumbria Specialist Emergency Care Hospital, UK; Marc Gimenez, ICU, Papworth Hospital NHS Foundation Trust, UK; Alan Pope, Critical Care Unit, Peterborough City Hospital, UK; Julie Camsooksai, Critical Care Unit, Poole Hospital NHS Trust, UK; David Pogson, Department of Critical Care, Queen Alexandra Hospital Portsmouth, UK; Kate Quigley, ICU, Queen Elizabeth Hospital, UK; Jenny
Ritzema, Critical Care Department, Queen Elizabeth Hospital, Gateshead, UK; Anil Hormis, Critical Care Unit, Rotherham NHS Foundation Trust, UK; Carole Boulanger, ICU, Royal Devon and Exeter NHS Foundation Trust, UK; M. Balasubramaniam, ICU and HCU, Royal Bolton NHS hospital trust, UK; Luke Vamplew, Critical Care Unit, Royal Bournemouth Hospital, UK; Karen Burt, Critical Care Unit, Royal Cornwall Hospital NHS Trust, UK; Daniel Martin, ICU, Royal Free London NHS Foundation Trust, UK; Irina Grecu, ICU, Royal Hampshire County Hospital, UK; Jayne Craig, ICU, Royal Lancaster Infirmary, UK; John Prowle, Adult Critical Care Unit, Royal London Hospital, UK; Nanci Doyle, ICU, Royal Surrey County Hospital, UK; Jonathon Shelton, Ward 38 ICU, Royal Victoria Infirmary, UK; Carmen Scott, Ward 18 ICU, Royal Victoria Infirmary, UK; Phil Donnison, ICU, Salisbury District Hospital, UK; Sarah Shelton, ICU, Sherwood Forest Hospitals NHS Foundation Trust, UK; Christian Frey, ITU/HDU, South Tyneside District Hospital, UK; Christine Ryan, GICU, St Georges Hospital, UK; Dominic Spray, Cardiothoracic ICU, St Georges Hospital, UK; Christine Ryan, Acute Dependency Unit, St Georges Hospital NHS Trust London, UK; Veronica Barnes, Neuro ICU, St Georges University Hospital NHS Foundation Trust, UK; Kerry Barnes, ITU, st helier hospital, UK; Stephanie Ridgway, Critical Care Unit, NHS Foundation Trust, Tameside General Hospital, UK; Rajnish Saha, Critical Care Unit, The Princess Alexandra NHS Hospital, UK; Linda Kent, ICU, The Royal Oldham Hospital, UK; Thomas Clark, ICU, Torbay Hospital, UK; James Wood, ICU, Tunbridge Wells Hospital, UK; Clare Bolger, General Intensive Care, Univeristy Hospital Southampton NHS Foundation Trust, UK; Christopher Bassford, General Critical Care, University Hospital Coventry, UK; Amanda Cowton, ICU, University hospital of North Durham, UK; john lewandowski, Critical Care Unit, University Hospital of North Tees, UK; Xiaobei Zhao, ICU (Level 6), Watford General Hospital / West Hertfortshire NHS trust, UK; Sally Humphreys, Critical Care, West Suffolk NHS Foundation Trust, UK; Susan Dowling, Ward 4E Critical Care unit, Whiston, UK; Neil Richardson, ICU, William Harvey Hospital, Ashford, UK; Andrew Burtenshaw, Critical Care Unit, Worcestershire Royal Hospital, UK; Carl Stevenson, ICU, Wye Valley NHS Trust, UK; Danielle Wilcock, Critical Care Unit, York Teaching Hospital NHS Foundation Trust, UK; Yuiry Nalapko, Anaesthesia and Intensive Care, Lugansk State Medical University, Ukraine.

\section{Conflict of interests}

The authors declare that they have no competing interests.

\section{Financial disclosure statement}

No (industry) sponsorship has been received for this investigatorinitiated study.

\section{References}

[1] de Rooij SE, Govers AC, Korevaar JC, Giesbers AW, Levi M, de Jonge E. Cognitive, functional, and quality-of-life outcomes of patients aged 80 and older who survived at least 1 year after planned or unplanned surgery or medical intensive care treatment. J Am Geriatr Soc 2008;56:816-22.

[2] Bagshaw SM, Webb SA, Delaney A, et al. Very old patients admitted to intensive care in Australia and New Zealand: a multi-centre cohort analysis. Crit Care 2009;13:R45.

[3] Pietilainen L, Hastbacka J, Backlund M, Parviainen I, Pettila V, Reinikainen M. Premorbid functional status as a predictor of 1-year mortality and functional status in intensive care patients aged 80 years or older. Intensive Care Med 2018;44:1221-9.

[4] Flaatten H, de Lange DW, Artigas A, et al. The status of intensive care medicine research and a future agenda for very old patients in the ICU. Intensive Care Med 2017;43:1319-28.

[5] Flaatten H, De Lange DW, Morandi A, et al. The impact of frailty on ICU and 30-day mortality and the level of care in very elderly patients $(>/=80$ years). Intensive Care Med 2017;43:1820-8.

[6] Chin-Yee N, D'Egidio G, Thavorn K, Heyland D, Kyeremanteng K. Cost analysis of the very elderly admitted to intensive care units. Crit Care 2017;21:109.

[7] Flaatten H, Oeyen S, deLange DW. Predicting outcomes in very old ICU patients: time to focus on the past? Intensive Care Med Aug 2018;44(8):1344-5. https://doi.org/ 10.1007/s00134-018-5262-1 Epub 2018 Jul 2.

[8] Guidet B, Leblanc G, Simon T, et al. Effect of systematic intensive care unit triage on long-term mortality among critically ill elderly patients in France: a randomized clinical trial. JAMA 2017;318:1450-9. 
[9] Vincent JL, Moreno R, Takala J, et al. The SOFA (Sepsis-related organ failure assessment) score to describe organ dysfunction/failure. On behalf of the working group on Sepsis-related problems of the European Society of Intensive Care Medicine. Intensive Care Med 1996;22:707-10.

[10] Knaus WA, Draper EA, Wagner DP, Zimmerman JE. APACHE II: a severity of disease classification system. Crit Care Med 1985;13:818-29.

[11] Le Gall JR, Lemeshow S, Saulnier F. A new simplified acute physiology score (SAPS II) based on a European/north American multicenter study. JAMA 1993:270:2957-63.

[12] Muessig JM, Nia AM, Masyuk M, et al. Clinical frailty scale (CFS) reliably stratifies octogenarians in German ICUs: a multicentre prospective cohort study. BMC Geriatr 2018;18:162.

[13] Guidet B, Flaatten $\mathrm{H}$, Boumendil A, et al. Withholding or withdrawing of lifesustaining therapy in older adults $(>/=80$ years) admitted to the intensive care unit. Intensive Care Med 2018;44:1027-38.

[14] Boumendil A, Somme D, Garrouste-Orgeas M, Guidet B. Should elderly patients be admitted to the intensive care unit? Intensive Care Med 2007;33:1252.

[15] Guidet B, de Lange DW, Flaatten H. Should this elderly patient be admitted to the ICU? Intensive Care Med Nov 2018;44(11):1926-8. https://doi.org/10.1007/ s00134-018-5054-7 (Epub 2018 Jan 22).

[16] Pearse RM, Moreno RP, Bauer P, et al. Mortality after surgery in Europe: a 7 day cohort study. Lancet 2012;380:1059-65.

[17] Nathanson BH, Higgins TL, Brennan MJ, Kramer AA, Stark M, Teres D. Do elderly patients fare well in the ICU? Chest 2011;139:825-31.

[18] Marty P, Roquilly A, Vallee F, et al. Lactate clearance for death prediction in severe sepsis or septic shock patients during the first 24 hours in intensive care unit: an observational study. Ann Intensive Care 2013;3:3.

[19] Masyuk M, Wernly B, Lichtenauer M, et al. Prognostic relevance of serum lactate kinetics in critically ill patients. Intensive Care Med 2019;45:55-61.

[20] Fried LP, Tangen CM, Walston J, et al. Frailty in older adults: evidence for a phenotype. J Gerontol A Biol Sci Med Sci 2001;56:M146-N156.

[21] Abellan van Kan G, Rolland Y, Bergman H, Morley JE, Kritchevsky SB, Vellas B. The I.a. N.a task force on frailty assessment of older people in clinical practice. J Nutr Health Aging 2008;12:29-37.

[22] Hope AA, Hsieh SJ, Petti A, Hurtado-Sbordoni M, Verghese J, Gong MN. Assessing the usefulness and validity of frailty markers in critically ill adults. Ann Am Thorac Soc 2017:14:952-9.

[23] Gilbert T, Neuburger J, Kraindler J, et al. Development and validation of a hospital frailty risk score focusing on older people in acute care settings using electronic hospital records: an observational study. Lancet 2018;391:1775-82.

[24] Rockwood K, Song X, MacKnight C, et al. A global clinical measure of fitness and frailty in elderly people. CMAJ 2005;173:489-95.
[25] Zampieri FG, Iwashyna TJ, Viglianti EM, et al. Association of frailty with short-term outcomes, organ support and resource use in critically ill patients. Intensive Care Med 2018;44:1512-20.

[26] Flaatten H, Clegg A. Frailty: we need valid and reliable tools in critical care. Intensive Care Med 2018;44:1973-5.

[27] Kim SW, Han HS, Jung HW, et al. Multidimensional frailty score for the prediction of postoperative mortality risk. JAMA Surg 2014;149:633-40.

[28] Chan DC, Tsou HH, Yang RS, et al. A pilot randomized controlled trial to improve geriatric frailty. BMC Geriatr 2012;12:58.

[29] McIsaac DI, Jen T, Mookerji N, Patel A, Lalu MM. Interventions to improve the outcomes of frail people having surgery: a systematic review. PLoS One 2017;12: e0190071.

[30] Zerah L, Dourthe L, Cohen-Bittan J, et al. Retrospective evaluation of a restrictive transfusion strategy in older adults with hip fracture. J Am Geriatr Soc Jul 2018;66 (6):1151-7. https://doi.org/10.1111/jgs.15371 (Epub 2018 Apr 20).

[31] Nguyen YL, Angus DC, Boumendil A, Guidet B. The challenge of admitting the very elderly to intensive care. Ann Intensive Care 2011;1:29.

[32] Angus DC. Admitting elderly patients to the intensive care unit-is it the right decision? JAMA 2017;318:1443-4.

[33] Eddleston JM, White P, Guthrie E. Survival, morbidity, and quality of life after discharge from intensive care. Crit Care Med 2000;28:2293-9.

[34] Dowdy DW, Eid MP, Sedrakyan A, et al. Quality of life in adult survivors of critical illness: a systematic review of the literature. Intensive Care Med 2005;31:611-20.

[35] Andersen FH, Flaatten H, Klepstad P, Romild U, Kvale R. Long-term survival and quality of life after intensive care for patients 80 years of age or older. Ann Intensive Care 2015;5:53.

[36] Guidet B, Vallet H, Boddaert J, et al. Caring for the critically ill patients over 80: a narrative review. Ann Intensive Care 2018;8:114.

[37] Leblanc G, Boumendil A, Guidet B. Ten things to know about critically ill elderly patients. Intensive Care Med 2017;43:217-9.

[38] Oeyen S, Vermeulen K, Benoit D, Annemans L, Decruyenaere J. Development of a prediction model for long-term quality of life in critically ill patients. J Crit Care 2018;43:133-8.

[39] Cuthbertson BH, Wunsch H. Long-term outcomes after critical illness. The best predictor of the future is the past. Am J Respir Crit Care Med 2016;194:132-4.

[40] Lecuyer L, Chevret S, Thiery G, Darmon M, Schlemmer B, Azoulay E. The ICU trial: new admission policy for cancer patients requiring mechanical ventilation. Crit Care Med 2007;35:808-14. 